\title{
Empirical Research on the Impact of Personalized Recommendation Diversity
}

\author{
Lin Zhang \\ Institute of Public Safety Research \\ Department of Engineering Physics \\ Tsinghua University \\ zhanglinthu@163.com
}

\author{
Qiang Yan \\ School of Economics and Management \\ Beijing University of Posts and \\ Telecommunications \\ yan@bupt.edu.cn
}

\author{
Junqiang Lu \\ Office of Procurement and Tendering \\ Beijing University of Posts and \\ Telecommunications \\ lujunqiang@bupt.edu.cn
}

\author{
Yongqiang Chen \\ Department of Mechanics and Engineering Science \\ College of Engineering \\ Peking University \\ chenyq@pku.edu.cn
}

\author{
Yi Liu \\ Institute of Public Safety Research \\ Department of Engineering Physics \\ Tsinghua University \\ liuyi@tsinghua.edu.cn
}

\begin{abstract}
Personalized recommendation has important implications in raising online shopping efficiency and increasing product sales. There has been wide interest in finding ways to provide more efficient personalized recommendations. Most existing studies focus on how to improve the accuracy of the recommendation algorithms, or are more concerned on ways to increase consumer satisfaction. Unlike these studies, our study focuses on the process of decision-making, using long tail theory as a basis, to reveal the mechanisms involved in consumers' adoption of recommendations. This paper analyzes the effect of personalized recommendations from two angles: product sales and ratings, and tries to point out differences in consumer preferences between mainstream products and niche products, high rating products and low rating products, search products and experience products. The study verifies that consumers demand diversity in the recommended content, and also provides suggestions on how to better plan and operate a personalized recommendation system.
\end{abstract}

\section{Introduction}

Personalized recommendation system can help consumers make purchase decisions [1], while promoting product sales [2]. It has been widely used in e-commerce sites. Most existing studies focus on improving the accuracy of personalized recommendation algorithms, or analyzing consumer satisfaction with the personalized recommendation based on perceived trust and perceived risk. While these efforts are important to finding new ways of enhancing the effect of personalized recommendation, they've ignored the variations within consumer product preference [3, 4]. If consumers are not satisfied with the recommendation products, these products can distract their attention and even cause consumer resentment [5].

Since this paper focuses on the process of decisionmaking and consumers' preference to study the impact of personalized recommendation diversity on the recommendation effect. Specifically, this study will answer the following questions.

1 Do sales and ratings of recommendation products have an impact on consumers' adoption of personalized recommendation?

2 Does personalized recommendation diversity improve the recommendation effect?

The specific contribution of this study contains three aspects. Firstly, in accordance with long tail theory, this research highlights the adoption mechanism of personalized recommendation from the process of decision-making. Secondly, it clearly shows the impact of recommendation product sales and ratings on the adoption of recommendation and points out the different preferences of consumers towards mainstream products and niche products, high score and low score products, and reveal consumers' demand for recommendation diversity. Third, this paper also analyzes the adoption of personalized recommendation of different types of products, and finds that the recommendation effect of experience products is better than the recommendation effect of search products. 
The conclusions of the study have practical reference value for the design and development of personalized recommendation mechanisms of $\mathrm{e}$ commerce websites and the improvement of the personalized recommendation diversity.

\section{Theoretical Foundation and Literature Review}

\subsection{Personalized recommendation effect}

Most personalized recommendation systems rely on accuracy to evaluate the effect of personalized recommendation [6]. Currently, recommendation accuracy is generally divided into prediction accuracy, classification accuracy, sorting accuracy, prediction scoring association, distance standardization indicators, half-life utility indicators [7]. However, a good recommendation system should not only focus on accuracy but also take into account the consumer satisfaction [8]. Through data analysis of 347 app users, $\mathrm{Xu}$ et al. find that satisfaction is the direct antecedents of intention to recommend [9]. Besides the indicators above, the adoption of personalized recommendation is also used to evaluate the effect of personalized recommendation [10].

\subsection{Personalized recommendation diversity}

While personalized recommendation diversity reduces accuracy to a certain degree but improves users' subjective evaluation of the recommendation system [11]. Some "dark information" that users may be interested in has been ignored, thus recommendation are unable to meet their real needs [12]. Fleder and Hosanagar prove that some of the common recommendation algorithms actually reduce the diversity of sales and create "rich get richer" effects for popular products [13]. More recently, the drawbacks of building recommendation engines focusing exclusively on accuracy maximization have been also widely explored and highlighted [14]. Ziegler shows that the users' perceived list diversity goes beyond accuracy [15]. To improve recommendation diversity is crucial for the user experience enhancement and the better understanding of user interests [16].

\subsection{Long tail theory}

Anderson proposed that recommendation tools can provide consumers with an extensive selection of commodities, thus increasing the product categories
[17]. The internet helps consumers search for more niche products fitted to their personal preferences and has thus changed their buying behavior. It means that as more and more obscure products are provided, the tail will steadily become longer and wider. Brynjolfsson et al. find specific evidence of the transformation from traditional markets to niche product markets [18]. Fleder and Hosanagar prove that if recommendation systems only choose to recommend products with high sales, it would lead to a higher sales concentration [13]. Thus, it is necessary to have a recommendation framework that recommends unpopular items meanwhile minimizing the accuracy loss [19].

\section{Research model and hypothesis}

\subsection{Research model}

As the Internet makes it easier for consumers to search for niche products that satisfy their personal preferences, the demand curve and consumers purchase behavior will change accordingly [17]. A wellperformed recommendation list should contain not only popular products, but also long tail products. As a result, e-commerce sites should recommend the "head" mainstream products to consumers as well as the "tail" niche products to meet the different preferences of different consumers. Long tail theory provides the theoretical foundation of this recommendation mode [19]. In addition, it has been confirmed that anchoring effect generally exists in the case of consumers facing multiple choices [20]. When consumers need to make a second choice in the same scenario of consumption, they tend to use their first decision as the anchor value. Therefore, the anchoring has a strong effect on consumer decision-making [21]. This study divides products into mainstream products and niche products, also divides products into high rating products and low rating products. Recommendation products sales (mainstream products/niche products) and recommendation products ratings (high rating products/low rating products) are the two variables manipulated in this study. Furthermore, studies show that online reviews and evaluations by consumers are different when purchasing search products and experience products [22, 23]. Thus, the study divides recommendation products into search products and experience products and chooses product type as the adjustable variable.

Based on the description above, this paper presents the research model shown in Figure 1. 


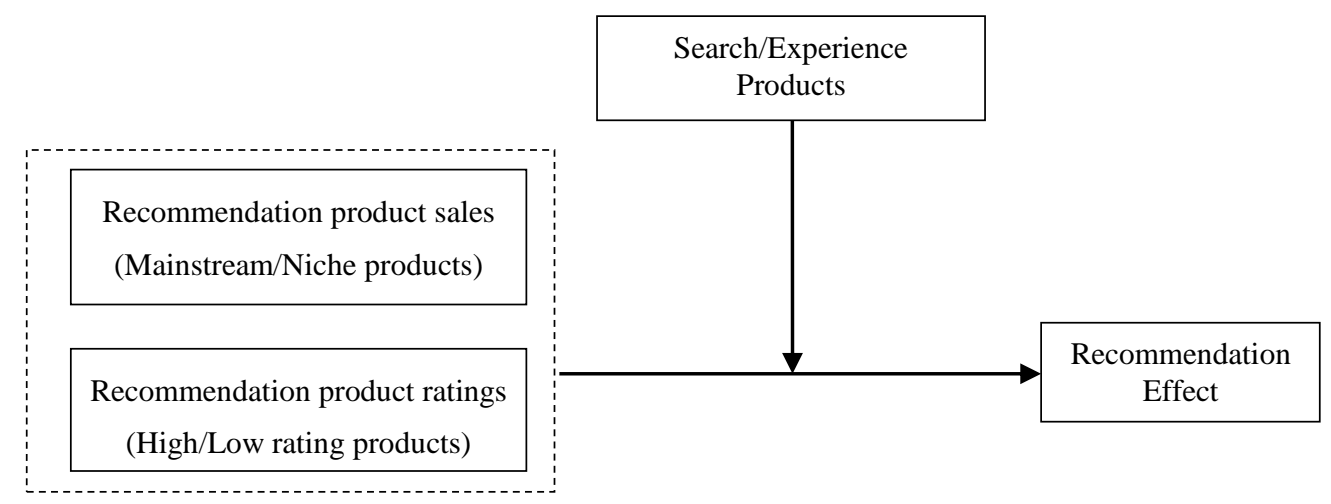

Figure 1. Research model

\subsection{Research Hypotheses}

Personalized recommendation usually has a positive impact on consumers' decision-making, but inappropriate product recommendation could have a negative impact on consumers [5]. Due to online shopping eliminates the physical limitations and cost constraints of consumer choice, the internet provide extensive selection for consumers that meet their needs [17]. If personalized recommendation system only recommends products with high sales, the sales concentration would be higher in that way [13]. Search and recommendation tools could influence online sales and consumers purchase patterns [24]. Consumers usually search and select products that match their preferences according to their interests and needs. Though the sales of mainstream products are very high, sales concentration in e-commerce sites will be greatly reduced as more niche products are provided. Ecommerce websites with high recommendation diversity will be favored by a large number of consumers with different preferences. Based on this, the study proposes the following hypothesis.

H1: There is better adoption by consumers when recommendation system recommends mainstream products and niche products simultaneously than that only recommends mainstream products or niche products.

Product reviews have an important impact on consumers' decision-making and sales [25]. Product reviews encompass two forms, written comments and product ratings [26]. Personalized recommendation systems with digital rating techniques greatly reduce the consumption time in online shopping [27]. Consumers usually refer to the ratings from others to make their own decisions when browsing products on e-commerce site. Moreover, the anchoring effect is ubiquitous in the process of decision-making. Consumers tend to use their first decision as the anchor value when they need to make a second choice in the same scenario of consumption [28]. Based on comparative consumption psychology, consumers will be involuntary to compare high rating products and low rating products when recommendation system recommends these two types of products simultaneously, and eventually buy more recommendation products. Thus, the study proposes the following hypothesis.

H2: There is better adoption by consumers when recommends high rating products and low rating products simultaneously than only recommends high rating products or low rating products.

Product reviews have a strong impact on decisionmaking, personalized recommendation systems provide recommendation service to target users by using the ratings from other consumers [25]. Synthesizing existing studies, high rating mainstream products will be increasingly favored by consumers who prefer mainstream products. Similarly, high rating niche products would be chosen and bought by those who prefer niche products. When recommendation system recommends high rating mainstream products and low rating niche products simultaneously, consumers will compare product sales, ratings and other information to make a final judgment on the recommendation products. Thus, the more diverse the recommendation products are, the easier for consumers to purchase recommendation products. Therefore, the study proposes the following hypothesis.

H3a: There is better adoption by consumers when recommendation system recommends high rating mainstream products and low rating niche products simultaneously than that only recommends high rating mainstream products or low rating niche products.

H3b: There is better adoption by consumers when recommendation system recommends high rating niche products and low rating mainstream products 
simultaneously than that only recommends high rating niche products or low rating mainstream products.

Existing studies prove that the impact of recommendation system on the recommendation effect varies from different types of products [29]. According to the difference in consumers' evaluation and use of online information, products can be divided into search products and experience products [30]. For search products, consumers can know product configurations easily by searching for related descriptions before purchasing the products. But for experience products, consumers need to query products experience posted online by other consumers to make a judgment on this type of products [31]. Compare with search products, consumers are willing to use more online information when purchasing experience products [22]. But compare with experiential products, when consumers are searching for relevant information about search products, consumers are more likely to search product attributes information when purchasing search products [32]. Consumers have different preferences for recommendation products due to the difference in using online information of different types of products, and it will further impact on the recommendation effect. This study proposes the following hypothesis.

H4: Consumers have stronger preferences to recommendation products that are experience products than search products.

\section{Empirical research}

\subsection{Research Methods}

This study used a combination of questionnaires and experiment. A report released by China Internet Network Information Center (CNNIC) proclaimed that as of December 2017, there are 506 million users who use mobile phone to shop online in China [33]. Mobile phones occupy a dominant position among the Internet devices [34]. Therefore, our experiment was based on simulated shopping application on mobile phones. Through combining products sales (mainstream products/ niche products) and products rating (high rating products/low rating products), we got the six recommendation product grouping as shown in Table 1. In view of the actual recommendation of e-commerce websites at present, we removed group 5 and group 6 , and set group 1-4 as the experimental groups. Due to this study focuses on the effects of different recommendation product portfolios on the recommendation effect, we identified four kinds of recommendation scenarios, and there were four categories and sixteen recommendation groups in this study, as shown in Table 2.

Table 1. Recommendation product grouping and realistic rationality

\begin{tabular}{ccc}
\hline & Recommendation product grouping & Realistic rationality \\
\hline 1 & High rating mainstream products \& High rating niche products & $\sqrt{ }$ \\
2 & High rating mainstream products \& Low rating mainstream products & $\sqrt{ }$ \\
3 & High rating mainstream products \& Low rating niche products & $\sqrt{ }$ \\
4 & High rating niche products \& Low rating mainstream products & $\sqrt{ }$ \\
5 & High rating niche products \& Low rating niche products & $X$ \\
6 & Low rating mainstream products \& Low rating niche products & $X$ \\
\hline
\end{tabular}

Table 2. Recommendation scenarios

\begin{tabular}{|c|c|c|}
\hline Recommendation Scenario & \multicolumn{2}{|c|}{ The proportion of recommendation products } \\
\hline $\mathrm{I}$ & $\mathrm{GZ}>\mathrm{GL}$ & $\mathrm{GZ}<\mathrm{GL}$ \\
\hline Recommend GZ\&GL & GZ: GL=8:0 GZ: GL=6:2 & GZ: GL $=2: 6 \quad$ GZ: GL $=0: 8$ \\
\hline II & $\mathrm{GZ}>\mathrm{DZ}$ & $\mathrm{GZ}<\mathrm{DZ}$ \\
\hline Recommend GZ\&DZ & GZ: DZ $=8: 0 \quad$ GZ: DZ $=6: 2$ & GZ: DZ $=2: 6 \quad$ GZ: DZ $=0: 8$ \\
\hline III & $\mathrm{GZ}>\mathrm{DL}$ & $\mathrm{GZ}<\mathrm{DL}$ \\
\hline Recommend GZ\&DL & GZ: DL=8:0 & $\mathrm{GZ}: \mathrm{DL}=2: 6$ \\
\hline IV & $\mathrm{GL}>\mathrm{DZ}$ & $\mathrm{GL}<\mathrm{DZ}$ \\
\hline Recommend GL\&DZ & GL: $\mathrm{DZ}=8: 0$ & GL: $D Z=2: 6 \quad$ GL: $D Z=0: 8$ \\
\hline
\end{tabular}

Mouse was selected as the representative search products, and book was selected as the representative experience products in this study. In this study, consumers' adoption of recommendation products was taken as the standard to measure recommendation effects. This study used the way in which Elberse [35], 
Tan and Netessine [36] defined the relative quantity of "head" and combined it with the definition of absolute quantity from Anderson [17]. Mouse were selected as the representative search products in this study from JD.com (one of the most famous e-commerce sites in China), and we identified 289 appropriate mouses. Since JD.com does not display the sales of each product, this study used the quantity of product reviews to replace product sales. Similarly, fiction books were selected as the representative experience products in this study, and 392 appropriate books were identified from JD.com. Elberse [35], Tan and Netessine [36] all use top $10 \%$ in product sales as the standard to measure the "head", the mainstream market share is about $67 \%-78 \%$ in their studies. Thus, we calculated the share of mainstream products and niche products in mouse and book markets. Results show that both in mouse or book markets, products which are in sales top 30 are mainstream products and the rest are niche products, as shown in Table 3.

At present, JD.com has adopt favorable reviews rate as the index of product rating. Due to consumer heterogeneity, and there is no specific definition of high rating and low rating in existing studies. Thus, this study selected the products which were higher than average number as high rating products and which were lower than average number as low rating products, which show in Table 4.

Table 3. Mainstream market share ratio of mouse \& book

\begin{tabular}{cccccc}
\hline The number of head & 10 & 20 & 30 & 40 & 50 \\
\hline Mainstream market share ratio of mouse & $49.38 \%$ & $67 \%$ & $75.6 \%$ & $80.98 \%$ & $84.28 \%$ \\
\hline Mainstream market share ratio of book & $57.86 \%$ & $69.84 \%$ & $76.42 \%$ & $79.85 \%$ & $82.83 \%$ \\
\hline
\end{tabular}

Table 4. The average number of favorable rating (Mouse/Book)

\begin{tabular}{ccc}
\hline \multirow{2}{*}{ Product type } & \multicolumn{2}{c}{ The average number of favorable ratings } \\
\cline { 2 - 3 } & Mainstream products & Niche products \\
\hline Mouse (search products) & $95.03 \%$ & $93.9 \%$ \\
Book (experience products) & $95.2 \%$ & $94.1 \%$ \\
\hline
\end{tabular}

\subsection{Experimental procedure}

We recruited 100 subjects to carry out a preliminary experiment before the formal experiment. The subjects were required to read instructions and purchasing tasks of the experiment after opening the link of web page. Then, they need to complete the purchasing tasks in the simulation shopping website. Finally, they were told to fill out the questionnaires. The pre-experiment verified that the shopping scenario in the experiment could make the subjects feel like they were doing actual shopping online while considering the recommendation products. The recommendation products in the experiment were recognized relatively easily by the users.

We forwarded the link of simulated shopping website through WeChat and other network channels to subjects. Two shopping scenarios were set in the experiment. Scenario 1-You need to purchase at least 5 different mouses as prizes and it's up to you to decide how many mouses to buy in this scenario. Scenario 2You are required to buy at least five different books, and it's up to 'you' to decide how many books to buy in this scenario. All subjects were be randomly assigned to different scenarios to complete their purchase task. Finally, the total number of subjects in the formal experiment was 1254, of which 1236 were valid and the valid rate was $98.56 \%$.

\section{Data analysis}

Firstly, we compared the number of recommendation products adopted by consumers in the situation that recommendation system only recommends mainstream products or niche products and that recommends the above two types of products simultaneously in recommendation scenario I. The average number and the one-way ANOVA of recommendation products adopted by consumers are shown in Table 5 and Table 6.

Table 5 and Table 6 show that the number of recommendation products adopted by consumers when recommendation system recommends mainstream products and niche products simultaneously is larger than the number when recommendation system only recommends mainstream products or recommends niche products $(\mathrm{p}<0.05)$. Thus, the results support hypothesis $\mathrm{H} 1$, that is, consumers tend to prefer adopting recommendations received in the situation that recommendation system recommended mainstream products and niche products simultaneously, thus the recommendation effect in this situation is relatively better. 
Table 5. The average number of recommendation products adopted by consumers in scenario I

\begin{tabular}{cccccc}
\hline $\begin{array}{c}\text { Recommendation } \\
\text { scenario }\end{array}$ & Product type & \multicolumn{3}{c}{ The average number of adopted recommendation products } \\
\hline & & GZ: GL=8:0 & GZ: GL=6:2 & GZ: GL=2:6 & GZ: GL=0:8 \\
& Search products & 1.78 & 2.54 & 2.19 & 1.58 \\
I & Experience products & 2.32 & 3.02 & 2.96 & 2.29 \\
& Total & 2.02 & 2.79 & 2.61 & 1.97 \\
\hline
\end{tabular}

Table 6. One-way ANOVA of recommendation effect in scenario I

\begin{tabular}{|c|c|c|c|c|c|c|c|}
\hline $\begin{array}{l}\text { Recommendation } \\
\text { scenario }\end{array}$ & Product type & & $\begin{array}{l}\text { Sum of } \\
\text { squares }\end{array}$ & df & $\begin{array}{l}\text { Mean } \\
\text { square }\end{array}$ & $\mathrm{F}$ & Significance \\
\hline \multirow{9}{*}{ I } & \multirow{3}{*}{$\begin{array}{l}\text { Search } \\
\text { products }\end{array}$} & Between groups & 22.504 & 3 & 7.501 & \multirow[t]{3}{*}{3.180} & \multirow[t]{3}{*}{.026} \\
\hline & & Within groups & 377.472 & 160 & 2.359 & & \\
\hline & & Sum & 399.976 & 163 & & & \\
\hline & \multirow{3}{*}{$\begin{array}{l}\text { Experience } \\
\text { products }\end{array}$} & Between groups & 20.936 & 3 & 6.979 & \multirow[t]{3}{*}{3.067} & \multirow[t]{3}{*}{.029} \\
\hline & & Within groups & 389.098 & 171 & 2.275 & & \\
\hline & & Sum & 410.034 & 174 & & & \\
\hline & \multirow{3}{*}{ Total } & Between groups & 43.482 & 3 & 14.494 & \multirow[t]{3}{*}{6.066} & \multirow[t]{3}{*}{.000} \\
\hline & & Within groups & 800.506 & 335 & 2.390 & & \\
\hline & & Sum & 843.988 & 338 & & & \\
\hline
\end{tabular}

We compared the number of recommendation products adopted by consumers in the situation that recommendation system only recommends high rating products or low rating products and system recommends the above two types of products simultaneously in recommendation scenario II. The average number and the one-way ANOVA of recommendation products adopted by consumers are shown in Table 7 and Table 8.

Table 7. The average number of recommendation products adopted by consumers in scenario II

\begin{tabular}{cccccc}
\hline $\begin{array}{c}\text { Recommendation } \\
\text { scenario }\end{array}$ & Product type & \multicolumn{4}{c}{ The average number of adopted recommendation products } \\
\hline \multirow{3}{*}{ II } & & GZ: GL=8:0 & GZ: GL=6:2 & GZ: GL=2:6 & GZ: GL=0:8 \\
& Search products & 1.97 & 1.92 & 1.67 & 1.46 \\
& Experience products & 2.87 & 2.82 & 2.24 & 2.17 \\
Total & 2.42 & 2.37 & 1.90 & 1.82 \\
\hline
\end{tabular}

Table 8. One-way ANOVA of recommendation effect in scenario II

\begin{tabular}{cccccccc}
\hline $\begin{array}{c}\text { Recommendation } \\
\text { scenario }\end{array}$ & Product type & & $\begin{array}{c}\text { Sum of } \\
\text { squares }\end{array}$ & df & $\begin{array}{c}\text { Mean } \\
\text { square }\end{array}$ & F & Significance \\
\hline \multirow{5}{*}{ II } & Search & Between groups & 6.729 & 3 & 2.243 & 1.086 & .357 \\
& Wroducts & Within groups & 336.708 & 163 & 2.066 & & \\
& Sum & 343.437 & 166 & & & \\
& Experience & Between groups & 15.694 & 3 & 5.231 & 1.831 & .144 \\
& Wroducts & Within groups & 419.975 & 147 & 2.857 & & \\
& & Sum & 435.669 & 150 & & & .032 \\
& Between groups & 22.824 & 3 & 7.608 & 2.972 & \\
& Total & Within groups & 803.871 & 314 & 2.560 & & \\
& Sum & 826.695 & 317 & & & \\
\hline
\end{tabular}

As seen in Table 7 and Table 8, there is no significant differences in these two situations, thus it rejects hypothesis $\mathrm{H} 2$. The results show that when recommendation system recommended high rating 
products and low rating products simultaneously, consumes are not willing to purchase more recommendation products. In light of this, the study proposes that although product rating could guide decision-making, consumers may pay more attention to other related factors (for instance, price, brands, etc.) [37, 38].

In order to validate $\mathrm{H} 3 \mathrm{a}$ and $\mathrm{H} 3 \mathrm{~b}$, we compared the number of recommendation products adopted by consumers in the situation that recommendation system only recommends high rating mainstream products or low rating niche products and system recommends the above two types of products simultaneously in recommendation scenario III, also compared the number of recommendation products adopted by consumers in the situation that recommendation system only recommends high rating niche products or low rating mainstream products and system recommends the above two types of products simultaneously in recommendation scenario $\mathrm{IV}$, and multiple comparisons of recommendation products adopted by consumers in different scenarios was done. The results are shown in Table 9, Table 10 and Table 11.

Table 9. The average number of recommendation products adopted by consumers in scenario III\&IV

\begin{tabular}{ccccc}
\hline Recommendation scenario & \multicolumn{4}{c}{ The average number of adopted recommendation products } \\
\hline \multirow{2}{*}{ III } & GZ: DL=8:0 & GZ: DL=6:2 & GZ: DL=2:6 & GZ: DL=0:8 \\
& 1.97 & 2.73 & 2.44 & 1.65 \\
IV & GL: DZ=8:0 & GL: DZ=6:2 & GL: DZ=2:6 & GL: DZ=0:8 \\
& 1.80 & 2.53 & 2.47 & 1.66 \\
\hline
\end{tabular}

Table 10. One-way ANOVA of recommendation effect in scenario III\&IV

\begin{tabular}{ccccccc}
\hline Recommendation scenario & & Sum of squares & df & Mean square & F & Significance \\
\hline \multirow{2}{*}{ III\&IV } & Between groups & 94.245 & 7 & 13.464 & 5.074 & .000 \\
& Within groups & 1514.982 & 571 & 2.653 & & \\
& Sum & 1609.226 & 578 & & & \\
\hline
\end{tabular}

Table 11. Multiple comparisons of recommendation products adopted by consumers in different scenarios

\begin{tabular}{ccccccc}
\hline & \multicolumn{3}{c}{ Multiple comparisons } \\
\hline $\begin{array}{c}\text { (I) Recommendation (J) Recommendation } \\
\text { group }\end{array}$ & $\begin{array}{c}\text { Mean } \\
\text { difference } \\
\text { group }\end{array}$ & $\begin{array}{c}\text { Standard } \\
\text { error }\end{array}$ & $\begin{array}{c}\text { Significance } \\
\text { (I-J) }\end{array}$ & $\begin{array}{c}\text { 95\% confidence } \\
\text { interval }\end{array}$ \\
& GZ:DL=6:2 & $-.763^{*}$ & .283 & .007 & -1.32 & -.21 \\
& GZ:DL=2:6 & -.471 & .270 & .082 & -1.00 & .06 \\
& GZ:DL=0:8 & .322 & .270 & .234 & -.21 & .85 \\
GZ:DL=8:0 & GL:DZ=8:0 & .168 & .271 & .534 & -.36 & .70 \\
& GL:DZ=6:2 & $-.563^{*}$ & .273 & .040 & -1.10 & -.03 \\
& GL:DZ=2:6 & -.501 & .274 & .068 & -1.04 & .04 \\
& GL:DZ=0:8 & .309 & .275 & .262 & -.23 & .85 \\
\hline GZ:DL=8:0 & $.763^{*}$ & .283 & .007 & .21 & 1.32 \\
& GZ:DL=2:6 & .293 & .276 & .288 & -.25 & .83 \\
GZ:DL=6:2 & GZ:DL=0:8 & $1.085^{*}$ & .276 & .000 & .54 & 1.63 \\
& GL:DZ=8:0 & $.932^{*}$ & .276 & .001 & .39 & 1.47 \\
& GL:DZ=6:2 & .200 & .279 & .473 & -.35 & .75 \\
& GL:DZ=2:6 & .262 & .280 & .349 & -.29 & .81 \\
& GL:DZ=0:8 & $1.072^{*}$ & .281 & .000 & .52 & 1.62 \\
\hline GZ:DL=8:0 & .471 & .270 & .082 & -.06 & 1.00 \\
& GZ:DL=6:2 & -.293 & .276 & .288 & -.83 & .25 \\
& GZ:DL=0:8 & $.792^{*}$ & .263 & .003 & .28 & 1.31 \\
& GL:DZ=8:0 & $.639^{*}$ & .263 & .016 & .12 & 1.16 \\
GL:DZ=6:2 & -.093 & .266 & .728 & -.62 & .43 \\
& GL:DZ=2:6 & -.031 & .267 & .909 & -.56 & .49
\end{tabular}




\begin{tabular}{|c|c|c|c|c|c|c|}
\hline & GL:DZ=0:8 & $.780^{*}$ & .268 & .004 & .25 & 1.31 \\
\hline \multirow{7}{*}{ GZ:DL=0:8 } & GZ:DL=8:0 & -.322 & .270 & .234 & -.85 & .21 \\
\hline & $\mathrm{GZ}: \mathrm{DL}=6: 2$ & $-1.085^{*}$ & .276 & .000 & -1.63 & -.54 \\
\hline & GZ:DL=2:6 & $-.792^{*}$ & .263 & .003 & -1.31 & -.28 \\
\hline & GL:DZ=8:0 & -.153 & .263 & .561 & -.67 & .36 \\
\hline & GL:DZ $=6: 2$ & $-.885^{*}$ & .266 & .001 & -1.41 & -.36 \\
\hline & GL:DZ=2:6 & $-.823^{*}$ & .267 & .002 & -1.35 & -.30 \\
\hline & GL:DZ $=0: 8$ & -.013 & .268 & .962 & -.54 & .51 \\
\hline \multirow{7}{*}{ GL:DZ=8:0 } & GZ:DL=8:0 & -.168 & .271 & .534 & -.70 & .36 \\
\hline & $\mathrm{GZ}: \mathrm{DL}=6: 2$ & $-.932^{*}$ & .276 & .001 & -1.47 & -.39 \\
\hline & GZ:DL=2:6 & $-.639^{*}$ & .263 & .016 & -1.16 & -.12 \\
\hline & GZ:DL $=0: 8$ & .153 & .263 & .561 & -.36 & .67 \\
\hline & GL:DZ $=6: 2$ & $-.732^{*}$ & .267 & .006 & -1.26 & -.21 \\
\hline & GL:DZ=2:6 & $-.670^{*}$ & .268 & .013 & -1.20 & -.14 \\
\hline & GL:DZ $=0: 8$ & .141 & .269 & .601 & -.39 & .67 \\
\hline \multirow{7}{*}{ GL:DZ=6:2 } & GZ:DL=8:0 & $.563^{*}$ & .273 & .040 & .03 & 1.10 \\
\hline & GZ:DL=6:2 & -.200 & .279 & .473 & -.75 & .35 \\
\hline & GZ:DL=2:6 & .093 & .266 & .728 & -.43 & .62 \\
\hline & GZ:DL=0:8 & $.885^{*}$ & .266 & .001 & .36 & 1.41 \\
\hline & GL:DZ=8:0 & $.732^{*}$ & .267 & .006 & .21 & 1.26 \\
\hline & GL:DZ=2:6 & .062 & .271 & .819 & -.47 & .59 \\
\hline & GL:DZ $=0: 8$ & $.872^{*}$ & .272 & .001 & .34 & 1.41 \\
\hline \multirow{7}{*}{ GL:DZ=2:6 } & GZ:DL=8:0 & .501 & .274 & .068 & -.04 & 1.04 \\
\hline & GZ:DL=6:2 & -.262 & .280 & .349 & -.81 & .29 \\
\hline & GZ:DL=2:6 & .031 & .267 & .909 & -.49 & .56 \\
\hline & $\mathrm{GZ}: \mathrm{DL}=0: 8$ & $.823^{*}$ & .267 & .002 & .30 & 1.35 \\
\hline & GL:DZ=8:0 & $.670^{*}$ & .268 & .013 & .14 & 1.20 \\
\hline & GL:DZ $=6: 2$ & -.062 & .271 & .819 & -.59 & .47 \\
\hline & GL:DZ=0:8 & $.810^{*}$ & .272 & .003 & .28 & 1.35 \\
\hline \multirow{7}{*}{ GL:DZ=0:8 } & GZ:DL=8:0 & -.309 & .275 & .262 & -.85 & .23 \\
\hline & GZ:DL=6:2 & $-1.072^{*}$ & .281 & .000 & -1.62 & -.52 \\
\hline & GZ:DL=2:6 & $-.780^{*}$ & .268 & .004 & -1.31 & -.25 \\
\hline & GZ:DL=0:8 & .013 & .268 & .962 & -.51 & .54 \\
\hline & GL:DZ=8:0 & -.141 & .269 & .601 & -.67 & .39 \\
\hline & GL:DZ $=6: 2$ & $-.872^{*}$ & .272 & .001 & -1.41 & -.34 \\
\hline & GL:DZ=2:6 & $-.810^{*}$ & .272 & .003 & -1.35 & -.28 \\
\hline
\end{tabular}

Table 9, Table 10 and Table 11 show that the adoption for recommends high rating mainstream products and low rating niche products simultaneously are higher than that of only recommends one type of products, and the difference is significant, thus it supports the hypothesis H3a. Similarly, the results also supports the hypothesis H3b. This reflects there is better adoption by consumers when recommendation system recommends two types of products simultaneously than that only recommends one type of products, and there is a positive interaction between product sales and ratings which impacts on the personalized recommendation effects.

To validate $\mathrm{H} 4$, bilateral $\mathrm{T}$-test was done on the number of recommended search products and experience products adopted by consumers of each recommendation group in different recommendation scenarios, as shown in Table 12.

Table 12 suggests that the adoption of experience products is better than search products. As a whole, the difference is significant, which verifies the hypothesis H4. The results show that when it comes to experience products and search products, the focus and decisionmaking mode by users is not the same. For experience products, consumers need to query product reviews posted online from other consumers to make decision, but search products do not have this characteristic. It reflects consumers are more likely to be influenced by recommendations when they browse experience products on e-commerce websites. 
Table 12. The adoption of recommended search products and experience products

\begin{tabular}{ccccc}
\hline \multirow{2}{*}{ Recommendation scenario } & \multicolumn{3}{c}{ The average number of adopted recommendation products } \\
& Search products & Experience products & t \\
\hline \multirow{4}{*}{ I } & GZ:GL=8:0 & 1.78 & 2.32 & $-1.958^{*}$ \\
& GZ:GL=6:2 & 2.54 & 3.02 & -.977 \\
& GZ:GL=2:6 & 2.19 & 2.96 & -1.562 \\
& GZ:GL=0:8 & 1.58 & 2.29 & $-2.220^{* *}$ \\
& GZ:DZ=8:0 & 1.97 & 2.87 & $-2.264^{* *}$ \\
II & GZ:DZ=6:2 & 1.92 & 2.82 & $-2.438^{* *}$ \\
& GZ:DZ=2:6 & 1.91 & 2.24 & -.791 \\
& GZ:DZ=0:8 & 1.46 & 2.17 & $-2.222^{* *}$ \\
& GZ:DL=8:0 & 1.59 & 2.34 & $-2.147^{* *}$ \\
III & GZ:DL=6:2 & 2.26 & 3.09 & $-1.942^{*}$ \\
& GZ:DL=2:6 & 1.97 & 2.61 & $-1.705^{*}$ \\
& GZ:DL=0:8 & 1.31 & 2.03 & $-1.854^{*}$ \\
& GL:DZ=8:0 & 1.46 & 2.16 & $-1.910^{*}$ \\
IV & GL:DZ=6:2 & 2.12 & 2.88 & -1.512 \\
& GL:DZ=2:6 & 2.14 & 2.81 & $-1.855^{*}$ \\
& GL:DZ=0:8 & 1.31 & 2.09 & $-2.321^{* *}$ \\
\hline
\end{tabular}

Note: $* \mathrm{p}<0.1, * * \mathrm{p}<0.05, * * * \mathrm{p}<0.01$

\section{Conclusions}

The specific contribution of this study are as follows. First, the paper reveals the adoption mechanism of personalized recommendation from the process of decision-making. Secondly, the paper analyzes the effect of personalized recommendation from the perspective of sales and ratings, and validate consumers' demand for recommendation diversity. Thirdly, this study also analyzes the adoption of personalized recommendation of different product types, and finds that the recommendation effect of experience products is better than that of search products. In addition, the study also has practical implications. Firstly, we should take full account of recommendation diversity when designing a personalized recommendation system. Secondly, this study emphasizes that we should make full use of the strong preference of experience products, and promote the sales of experience products through personalized recommendation. For search products, except for improving the recommendation algorithm, we need to explore other possible strategies and make use of marketing methods to promote product sales.

There are some limitations in this study. First, this study selects one type of product as the representative of search products and experience products. Therefore, future work could select a variety of representative products to eliminate the impact of product selection difference. Secondly, this study verified hypotheses with simulated online shopping sites. Future research could obtain more objective data through $\mathrm{A} / \mathrm{B}$ research method in a real shopping environment.

\section{Acknowledgements}

This work is funded by National Key R\&D Program of China (No.2018YFC0809700, No.2017YFC0803300), National Natural Science Foundation of China (No.71804083, No.91646101, No.71673158), and National Social Science Foundation of China (No. 17AGL026).

\section{References}

[1] B. Xiao and I. Benbasat, "E-commerce product recommendation agents: use, characteristics, and impact", MIS Quarterly, 2007, 31(1): pp. 137-209.

[2] G. Häubl and K.B. Murray, "Double agents: assessing the role of electronic product recommendation systems", Sloan Management Review, 2006, 47(3): pp. 8-12.

[3] D.H. Lee and P. Brusilovsky, "Improving personalized recommendations using community membership information", Information Processing \& Management, 2017, 53(5): pp. 1201-1214.

[4] C. Li and J. Liu, "A name alone is not enough: A reexamination of web-based personalization effect", Computers in Human Behavior, 2017, 72: pp. 132-139.

[5] G.J. Fitzsimons and D.R. Lehmann, "Reactance to recommendations: When unsolicited advice yields contrary responses", Marketing Science, 2004, 23(1): pp. 82-94.

[6] S.L. Huang, "Designing utility-based recommender systems for e-commerce: Evaluation of preference-elicitation methods", Electronic Commerce Research \& Applications, 2011, 10(4): pp. 398-407.

[7] M.K. Najafabadi, et al., "Improving the accuracy of collaborative filtering recommendations using clustering and association rules mining on implicit data", Computers in Human Behavior, 2017, 67(C): pp. 113-128.

[8] T. Liang, H. Lai and Y. Ku, "Personalized content 
recommendation and user satisfaction: Theoretical synthesis and empirical findings", Journal of Management Information Systems, 2006, 23(3): pp. 45-70.

[9] C. Xu, D. Peak and V. Prybutok, "A customer value, satisfaction, and loyalty perspective of mobile application recommendations", Decision Support Systems, 2015, 79(C): pp. 171-183.

[10] Q. Yan, et al., "Effects of product portfolios and recommendation timing in the efficiency of personalized recommendation", Journal of Consumer Behaviour, 2016, 15(6): pp. 516-526.

[11] Z. Zhang, X. Zheng and D.D. Zeng, "A framework for diversifying recommendation lists by user interest expansion", Knowledge-Based Systems, 2016, 105: pp. 8395.

[12] N. Hurley and M. Zhang, "Novelty and diversity in top$\mathrm{n}$ recommendation--analysis and evaluation", ACM Transactions on Internet Technology (TOIT), 2011, 10(4): pp. 14.

[13] D. Fleder and K. Hosanagar, "Blockbuster Culture's Next Rise or Fall: The Impact of Recommender Systems on Sales Diversity", Social Science Electronic Publishing, 2009, 55(5): pp. 697-712.

[14] G. Adomavicius and Y. Kwon, "Maximizing aggregate recommendation diversity: A graph-theoretic approach", in ACM Conference on Recommender Systems. 2011. p. 3-10.

[15] C. Ziegler, et al., "Improving recommendation lists through topic diversification", in International Conference on World Wide Web. 2005, ACM. p. 22-32.

[16] L. Hou, et al., "Solving the stability-accuracy-diversity dilemma of recommender systems", Physica A Statistical Mechanics \& Its Applications, 2016, 468.

[17] C. Anderson, "The long tail: Why the future of business is selling more for less". 2006, New York: Hiperion.

[18] E. Brynjolfsson, Y.J. Hu and M.D. Smith, "From niches to riches: Anatomy of the long tail", Sloan Management Review, 2006, 47(4): pp. 67-71.

[19] S. Wang, et al., "Multi-objective optimization for long tail recommendation", Knowledge-Based Systems, 2016, 104 : pp. 145-155.

[20] D. Mochon and S. Frederick, "Anchoring in sequential judgments", Organizational Behavior and Human Decision Processes, 2013, 122(1): pp. 69-79.

[21] B.M. Turner and D.R. Schley, "The anchor integration model: A descriptive model of anchoring effects", Cognitive Psychology, 2016, 90: pp. 1-47.

[22] L.T. Bei, E.Y.I. Chen and R. Widdows, "Consumers' Online Information Search Behavior and the Phenomenon of Search vs. Experience Products", Journal of Family \& Economic Issues, 2004, 25(4): pp. 449-467.

[23] J. Luan, et al., "Search product and experience product online reviews: An eye-tracking study on consumers' review search behavior", Computers in Human Behavior, 2016, 65: pp. 420-430.

[24] P. De, Y. Hu and M.S. Rahman, "Technology usage and online sales: An empirical study", Management Science, 2010, 56(11): pp. 1930-1945.

[25] S. Liu, et al., "Identifying effective influencers based on trust for electronic word-of-mouth marketing: A domainaware approach", Information Sciences, 2015, 306: pp. 34-52. [26] A. Davis and D. Khazanchi, "An empirical study of online word of mouth as a predictor for multi-product category e-commerce sales", Electronic Markets, 2008, 18(2): pp. 130-141.

[27] C. Scaffidi, et al., "Red Opal: product-feature scoring from reviews", in ACM Conference on Electronic Commerce. 2007, ACM. p. 182-191.

[28] Y. Jiang, R. Coulter and S. Ratneshwar, "Consumption decisions involving goal tradeoffs: The impact of one choice on another", Advances in Consumer Research, 2005, 32: pp. 206-211.

[29] J. Wang, B. Sarwar and N. Sundaresan, "Utilizing related products for post-purchase recommendation in ecommerce", in ACM Conference on Recommender Systems. 2011, ACM: Chicago, USA. p. 329-332.

[30] P. Nelson, "Information and consumer behavior", Journal of political economy, 1970, 78(2): pp. 311-329.

[31] L.R. Klein, "Evaluating the potential of interactive media through a new lens: Search versus experience goods", Journal of business research, 1998, 41(3): pp. 195-203.

[32] L. Huang, et al., "Comprehension and assessment of product reviews: A review-product congruity proposition", Journal of Management Information Systems, 2013, 30(3): pp. 311-343.

[33] CNNIC, "The 41th statistic report of China Internet network development state". 2018, China Internet Network Information Center: Beijing.

[34] M. Gupta, et al., "Analysis and characterization of comparison shopping behavior in the mobile handset domain", Electronic Commerce Research, 2017, 17(3): pp. 521-551.

[35] A. Elberse, "Should you invest in the long tail?", Harvard business review, 2008, 86(7/8): pp. 88 .

[36] T.F. Tan and S. Netessine, "Is Tom Cruise threatened? Using Netflix Prize data to examine the long tail of electronic commerce". 2009: Philadelphia.

[37] B. Matsumoto and F. Spence, "Price beliefs and experience: Do consumers' beliefs converge to empirical distributions with repeated purchases?" Journal of Economic Behavior \& Organization, 2016, 126: pp. 243-254.

[38] Y.K. Saini and J.G. Lynch, "The effects of the online and offline purchase environment on consumer choice of familiar and unfamiliar brands", International Journal of Research in Marketing, 2016, 33(3): pp. 702-705. 